\title{
Knee Joint
}

National Cancer Institute

\section{Source}

National Cancer Institute. Knee Joint. NCI Thesaurus. Code C32898.

A joint connecting the lower part of the femur with the upper part of the tibia. The lower part of the femur and the upper part of the tibia are attached to each other by lig aments. Other structures of the knee joint include the upper part of the fibula, located below and parallel to the tibia, and the patella which moves as the knee bends. 